\title{
Public Health and the Environment: How Transdisciplinarity Can Support Large Scale E-Government Projects
}

\author{
Inas $\mathrm{Ezz}^{1,2,3}$ and Anastasia Papazafeiropoulou ${ }^{2}$ \\ ${ }^{1}$ Sadat Academy of Management Sciences, Cairo, Egypt \\ ${ }^{2}$ Brunel University, London, UK \\ ${ }^{3}$ The German University in Cairo (GUC)
}

\begin{abstract}
Environmental projects are large scale public sector projects which demand the participation of a number of public and private sector agents working harmoniously towards the public good. Public health and damaging environmental influences is a social problem that has attracted the attention of governments worldwide and has been seen as a stepping stone to sustainable development. In this paper we look at electromagnetic fields as health hazards and technologies that have been developed to solve these problems such as biogeometry and geographical information systems. Based on these technologies we suggest a framework for a project that that can be used to advance the research in transdisciplinary large scale projects related to public health. This framework is contributing to the knowledge of managing large scale e-government projects related to public health. Our ideas can be extended to other public sector projects as well as various geographical settings.
\end{abstract}

Keywords: E-government, Large scale projects, Public health, Environmental factors, Transdiciplinary projects.

\section{Introduction}

Hughes and Johnston (2005) have recognized that sustainable development is now as much about social equity-for current generations-as about efficient resource-use and conservation of natural resources for future ones. One of the aspects of sustainable development is the threat of health hazards as the links between health and economic development have become increasingly recognized, especially with respect to the contribution of health to poverty reduction. The term health hazards includes but is not limited to the exposure to carcinogenic or toxic substances, which may be present in air, soil, water, foods, as consequence of anthropic activities, including the risk associated with nuclear power plants and electromagnetic fields. Information technology applied and used by governments worldwide plays a crucial role in resolving the problem of sustainable development. For example, a complete Environmental and Human Health Risk Assessment requires the integration of information on environmental and chemicals database, inter and intra media dispersion models output, site

Copyright (C) 2011 Inas Ezz, and Anastasia Papazafeiropoulou. This is an open access article distributed under the Creative Commons Attribution License unported 3.0, which permits unrestricted use, distribution, and reproduction in any medium, provided that original work is properly cited. Contact author: Anastasia Papazafeiropoulou E-mail: anastasia.papazafeiropoulou@brunel.ac.uk 
description maps and demographic database. In the last years, the use of information technology and systems supporting this process has been extensively used, especially geographic information systems (GIS). For example, the GIS- based maps identify high exposure areas for policy makers and planners in a simple and realistic manner. Satellites with television, spectrometric, and photographic equipment are the main means of continuous control of the state of natural systems of our planet. The GIS spatial database does not just allow combining different health hazards but also other variables necessary for the assessment of the social-geophysical factors, which depend on the location of the area of interest and its population such as proximity to the radiation risk sites and population density in this area. Although the extensive work concerning some health hazards, these efforts are isolated and need integration. This paper suggests an integrated transdisciplinary framework using GIS in the context of health hazards, aiming to assist in suggesting a framework that can be used by governments worldwide to apply sustainable development practices.

Lawrence and Després (2004) define transdisciplinarity is a word à la mode. However, few are aware of the context of its origins, of what it meant at that time, and how it has evolved as a concept in recent decades. While interdisciplinary research concerns several disciplines, transdisciplinary research implies crossing the boundaries between disciplines.

It defines a mediation space between them. Transdisciplinary research focuses on the organisation of knowledge around complex heterogeneous domains, rather than the disciplines and subjects into which knowledge seems inevitably to become organised in academic settings (Nowotny et al, 2001), 'transcending' the academic disciplinary structure. Horlick-Jones and Sime (2004) believe that transdisciplinarity has been hailed as a potentially effective means of addressing increasingly complex societal problems, the nature of which cut across the boundaries between orthodox disciplinary knowledge. From Galliers (2004) perspective, transdisciplinarity is about joint problem solving among science, technology and society. In the 'ideal case', this problem solving process is preceded by an exercise of joint problem defining. The success of the transdisciplinary approach is based on the preparedness of all participants (all disciplines, the public, and the politicians) to work in an atmosphere of transparency, trust and openness, trying to balance personal interests with interests for the common good. This means that the transdisciplinary approach, on the other hand, requires careful preparation and a willingness to understand the language and underlying philosophies of one's colleagues (Newell \& Galliers, 2000).

The paper is structured as follows. In the next section we examine the problem of electromagnetic fields as health hazards that need to be addressed by governments today. Then in section 3 we present the need to transdiciplinarity research when it comes to the application of large scale projects on public health. Finally, we suggest a framework with the specific example of an application for prevention of public health hazards (section 5) and we conclude with current limitations and future projections.

\section{Previous Research on Electromagnetic Fields as Health Hazards}

There has been concern about possible health consequences from exposure to the radiofrequency (RF) fields produced by wireless technologies. According to the WHO (2006) mobile telephony is now commonplace around the world. This wireless technology relies upon an extensive network of fixed antennas, or base stations, relaying information with (RF) signals.

Over 1.4 million base stations exist worldwide and the number is increasing significantly with the introduction of third generation technology. Other wireless networks that allow high-speed internet 
access and services, such as wireless local area networks (WLANs), are also increasingly common in homes, offices, and many public areas (airports, schools, residential and urban areas). As the number of base stations and local wireless networks increases, so does the RF exposure of the population. This fact sheet reviews the scientific evidence on the health effects from continuous low-level human exposure to base stations and other local wireless networks.

The impact of electromagnetic fields exposure on health has been discussed during the last few years from different perspectives. They range for listing electromagnetic fields as a potential health hazard to listing several diseases associated with the exposure. Some studies such as (Röösli, 2008), suggest that some more sophisticated study design is needed to bridge this research gap. Otto and Hlendahl (2007) record threats of potential diseases due to the magnetic and electromagnetic fields (EMF).In the context of low-frequency EMF, they mention that the results of epidemiological research with respect to childhood leukaemia prompted the International Agency for Research on Cancer (IARC) in 2001 to classify these fields as "possibly carcinogenic to humans".

\section{Biogeometry and Electromagnetic Health Hazards}

Electro-Smog as a subtle pollution has become one of the increasing problems inside our built environments. It is responsible for a condition known as electro hypersensitivity (EHS) as it is now being referred to by the Department of Health, the Health Protection Agency (HPA) and the World Health Organization (WHO).

Most of the solutions to Electro-Smog focus on reducing the radiation exposure and the number of electrical and wireless appliances despite their major role in our daily life. Using energy sciences such as BioGeometry, the harmful effects of electro smog will be neutralized. BioGeometry ${ }^{\circledR}$ uses specially designed shapes programmed according to a new 'Physics of Quality' to induce harmony in all levels of subtle energy in the environment. (Farouh, 2009)

According to Karim (2002), Karim (2007), and Farouh (2009) BioGeometry ${ }^{\circledR}$ energyquality balancing solutions are being applied to architecture, telecom networks, industrial design, boats and airplanes to transmute the effects of environmental energy disturbances from sources such as electro-magnetic radiation, structural design, and cosmic and earth-energy radiation. BioGeometry® science was used to solve the electro magnetic harmful hazards in two Swiss villages, Hemberg followed by Hirschberg. BioGeometry ${ }^{\circledR}$ uses the energy principles of geometrical shapes to balance biological energy systems within the overall framework of environmental energy interactions. According to Gilbert (2008), after a powerful cell phone tower was put in the middle of the Swiss city of Hemberg, residents began to fall ill. Animals and birds were seen to leave the area, and those confined to pens suffered miscarriages. The solutions provided in Hemberg were based on the placement of specially designed geometrical shapes in certain locations that radiate a harmonizing quality into the electromagnetic fields that propagate them into the environment. This project was initiated in 2003 by the Mediation authority and Swisscom. After the BioGeomtrical solutions the quality of life was completely changed and improved like health problems, psychological complains etc. In November 2005 the local government of Appenzell IR commissioned the BioGeometry® researchers to solve the long standing electro-sensitivity problems in the area of Hirschberg, Switzerland. The success was repeated again and hailed in the media. The fact that one can reduce the harmful side effects of electro-sensitivity without reducing the amount of electromagnetic radiation was a perfect environmental solution compatible with modern technology. 
During the last years, there has been growing attention to Biogeometry as a tool for health hazards reduction in several studies such as Dabaeh, (2006), Shiha (2009), Farouh (2008), and Abdel Aaal (2009) addressing the reduction of technological hazards through architectural designs with Biogeometry support in different contexts; $\mathrm{Al}$ Borolosy (2007), exploring the origins of architecture in different civilizations relating it to Biogeometry; Wafa (2009), proposing a framework for architectural design using Biogeometry concepts, Ahmed, (2004) and Al Sawy (2004), addressing very important issue concerning health hazards caused by artificial energy sources such as electrical devices and depending on the degree of pollution causing several diseases such as Alzheimer, cancer, headaches, fatigue and abortion. Al Morsy (2007) highlights the issue of reducing non-physical hazards through Biogeometry.

\section{The Role of Geographical Information Systems (GIS) in Public Health}

As Kistemann et al (2002) clarify; the domain of health is no typical area to apply Geographical Information Systems (GIS). In environmental sciences, GIS have been widely used to analyze a huge variety of land characteristics, and to solve problems related to human activities (Carlon et al, 2001, Facchinelli et al, 2001, Thums and Farago, 2001, Nam et al, 2003, Blanco and Cooper, 2004 and Elbir, 2004). Nevertheless, the recent development clearly shows that also within the domains of environmental health, disease ecology and public health GIS have become an indispensable tool for processing, analyzing and visualizing spatial data. In the field of geographical epidemiology, GIS are used for drawing up disease maps and for ecological analysis. The striking advantages of GIS for the disease mapping process are the considerably simplified generation and variation of maps as well as a broader variety in terms of determining area units. In the frame of ecological analysis, GIS can significantly assist with the assessment of the distribution of health-relevant environmental factors via interpolation and modeling.

On the other hand, the GIS-supported methods for the detection of striking spatial patterns of disease distribution need to be much improved. An important topic in this respect is the integration of the time dimension. The increasing use of remote sensing as well as the integration into internet functionalities will stimulate the application of GIS in the field of Environmental Health Sciences (EHS). In future, the integration and analysis of healthrelevant data in one single data system will open up many new research opportunities.

In the context of health risk assessment, GIS have been used for quantifying the human health risk through a system able to manage all the steps in a georeferenced structure (Bagli et al, 2004). Scoggins (2004) presents a study showing the use of GIS in the context of air pollution that relates ambient air pollution levels to mortality in Auckland, New Zealand, Urban airshed modeling and GIS-based techniques to quantify long-term exposure to ambient air pollution levels and associated mortality. The GIS-based exposure maps identify high exposure areas for policy developers and planners in a simple and realistic manner. Taken together with overseas studies the study provides additional evidence that long-term exposure to poor air quality, even at levels below current standards, is a hazard to the public health.

\section{The Need for Transdisciplinarity in Large Scale Public Health Projects}

Ezz et al (2006) have highlighted the need of transdisciplinary research in the context of large scale ICT and information systems projects. Bruce et al (2004) highlight Hicks and Katz (1996) arguments concerning increasing calls for more interdisciplinary approaches to problems, along with encouragement for greater collaboration and networking among institutions and 
researchers. Such encouragement is often based on the assumption that the research will contribute to more effective innovation and enhanced competitiveness. Pressure to encourage interdisciplinary research also comes from the need to solve complex socioscientific problems, where one discipline on its own cannot provide an answer. However, this perceived need for interdisciplinary research, despite considerable financial encouragement and verbal exhortation is not being met by the research community, particularly when it comes to research which crosses the boundaries between natural sciences and social sciences (The Royal Society, 1996).

Existing research on experience gained from transdisciplinary projects shows the challenges faced by the project teams. For example Antrop and Rogge (2006) present a case study in urban planning, where while integration worked smoothly amongst the researchers, the collaboration was much more difficult with the program team and local stakeholders. There were several reasons for this.

The expectations of the program team were very high and it was not yet clear how the results of the study would be integrated in the whole of the project. The challenges could be summed up as follows:

- Too high expectations by the program team.

- The unclear definition of the end-users of the report.

- The lack of a common language: Difficulties in communication occurred mainly between the program team and research team and between the program team and the local stakeholders.

- Too limited time for communication.

Further challenges are discussed by Tress et al (2005) including that interdisciplinary rural studies often lack a strategy on how to make integration work in their project. Two main types of design and management for integrative studies can be distinguished: the parallel design and the integrated design. In the parallel project design, disciplinary subprojects run parallel to each other. Subprojects come together late in the project process and try to integrate their results. Contributions of the single subprojects are still identifiably in the end-product.

Ezz et al (2006) give an example of the need for transdisciplinary research in the context of sustainable development in the context of integrated coastal zone management (ICZM). It is also clear through the literature review that there is still a need for transdisciplinary research models to support this complex and challenging task.

As the researchers mention, one of the main challenges of ICZM for sustainable development as a problem is that it necessitates the integration not only between different sectors but also, the integration among:

1) different coastal and marine sectors,

2) land and ocean sides,

3) science-management,

4) different nations (international), And

5) inter-government.

However, lack of co-operation between involved agencies is one of the challenges as this is far beyond the concept of integrated management. Thus we can see ICZM as a management and collaboration problem.It needs extraordinary management approach to deal with it. We argue that collaboration research efforts should be extended to the process centred view to mange country's resources, in the context of sustainability in general and ICZM in particular.

The challenge is also of how can these different efforts be integrated, whether from 
the technological, managerial, or transdisciplinary point of view? CecezKecmanovic (2006) argues that conceiving IS as a multi-disciplinary field is problematic.

However, multi-disciplinarity nature necessitating transdisciplinarity in the case of IS may mean openness to the wealth of knowledge from other disciplines necessary to deal competently with the heterogeneity and complexity of the IS phenomena. It also may mean cooperative relationships with other disciplines and constructive dialogues.

\section{Using Technology to Tackle Public Health Issues in Transdiscipline Projects}

Lawrence and Després (2004) discuss some key questions about the natural and humanmade environment, at whatever geographical scale; need to be understood by innovative concepts and methods. This stems from the fact that the capacity of human societies to deal with environmental questions (such as climate change, health, land-use, forestry management, renewable and non-renewable resources, housing, poverty and urban planning) are insufficient even though many professionals are convinced that they have the "right answers". The incapacity to deal with the above-mentioned problems is related to their complexity, to the compartmentalization of scientific and professional knowledge, to the sectoral division of responsibilities in contemporary society, and to the increasingly diverse nature of the societal contexts in which people live. In addition, the lack of effective collaboration between scientists, professionals and policy decision-makers has led to the "applicability gap" in sectors that deal with both the natural and human-made environment. There is an urgent need for innovative approaches in many situations, such as the blatant failure of the wealthiest countries of the world to provide all citizens with secure employment, affordable housing and appropriate health care that meet at least minimal requirements.
As Kistemann et al (2002) argue environmental health sciences (EHS) are dealing with the effect of natural and social environment on human health. Reflecting the complex and heterogeneous character of this structure, many sciences make specific contributions to its analysis, among them environmental hygiene and environmental medicine, toxicology and epidemiology, but also natural sciences, economics and social sciences. In many cases, the investigation requires a close interdisciplinary cooperation (Eikmann and Herr, 2001). If the aspect of spatial relation between human health and environmental factors is to be dealt with, the expertise of geographical science as being focused on a spatial approach is required. Along with the reintroduction of classical literature into medicine and the ${ }^{\mathrm{T}}{ }^{\mathrm{M}}$ neo-Hippocratic $\int$ refocusing since the 18th century, the notion that place was a type of data: on one hand geometric data which are the co-ordinates of points defining also curves and areas and on the other hand the attribute data containing the factual information.

Thus, this area calls for transdisciplinary research, which focuses on the organization of knowledge around complex heterogeneous domains, rather than the disciplines and subjects into which knowledge seems inevitably to become organized in academic settings (Nowotny et al, 2001), 'transcending' the academic disciplinary structure. Further, it tackles complexity in science and it challenges knowledge fragmentation (e.g. Klein, 2004; Ramadier, 2004). It deals with research problems and organizations that are defined from complex and heterogeneous domains (e.g. HorlickJones \& Sime, 2004). Beyond complexity and heterogeneity, this mode of knowledge production is also characterized by its hybrid nature, non-linearity and reflexivity, transcending any academic disciplinary structure (Balsiger, 2004).

Some authors such as Hochtel et al (2006) have applied a theoretical concept of 
transdisciplinarity by presenting the successive work stages. It demonstrates why and how transdisciplinary methodology is to be applied. The transdisciplinary strategy was adopted since it enables researchers to cross disciplinary borders and to deal with extra-scientific "real world problems". In the context of health hazards, the framework presented by Hochtel et al (2006) applies, as we are dealing with the many sources and pathways of single agents which is a complex process-the complexity is magnified by several orders if considering the effects on health of housing or transport, urbanization and globalization, or changes to the ecosystem and to ecological processes. Health and environmental issues are becoming increasingly complex, crosscutting, and inter-related. (Schirnding, 2002) As been addressed in the above section the GIS can be used an integrator, in this case. The use of GIS is not limited to identify the combinatory health hazards per geographical area, but also for:

- Monitoring the application current agreed upon hazards/ laws

- Identifying new potential hazards

- Identifying new patterns

- Identifying new laws

- Healthcare planning (hospitals distribution, equity)

- $\quad$ Land use

- Crisis management

\section{Suggested Framework}

According to Caro (2008), several e-health networks in Canada, Germany, Sweden and the United Kingdom have been implemented. These components must transcend the boundaries of e-networks to engage and integrate transcendent forces in the form of public governance agents rooted in larger socio-political environments. In effect, information system professionals must acquire transcendent knowledge and skill sets to engage the "transgenic" forces, or key socio-political elements, that are critical in evolving inter-sectorial e-networks. Engaging and co-opting these transgenic forces appear to be particularly important in national health care systems, where public governance is a key socio-political value.

The framework will be investigated through the initiation of the infrastructure for a trasdisciplinarity e-health community in the Mediterranean region and other European and non-European partners; using the stateof the art technology in the field and with reusability in mind. Based on sustainable development thinking, the proposed community will not just address traditional health related projects but also prevention through understanding, elimination and prevention of health hazards, the impact of the proposed community will be related to environmental issues as well. The proposed community is planned to develop an underlying large scale information systems project based on various ICT technologies and systems such as but not limited to GIS integrated technical and non technical infrastructure, taking the expertise of other networks of excellence of previous European projects into consideration. This means that TREIHT is going to be piloting and implementing the ICT expertise in other environment such as Egypt. This will definitely add to those technologies, while implementing them in challenging environments such as those of developing countries. 


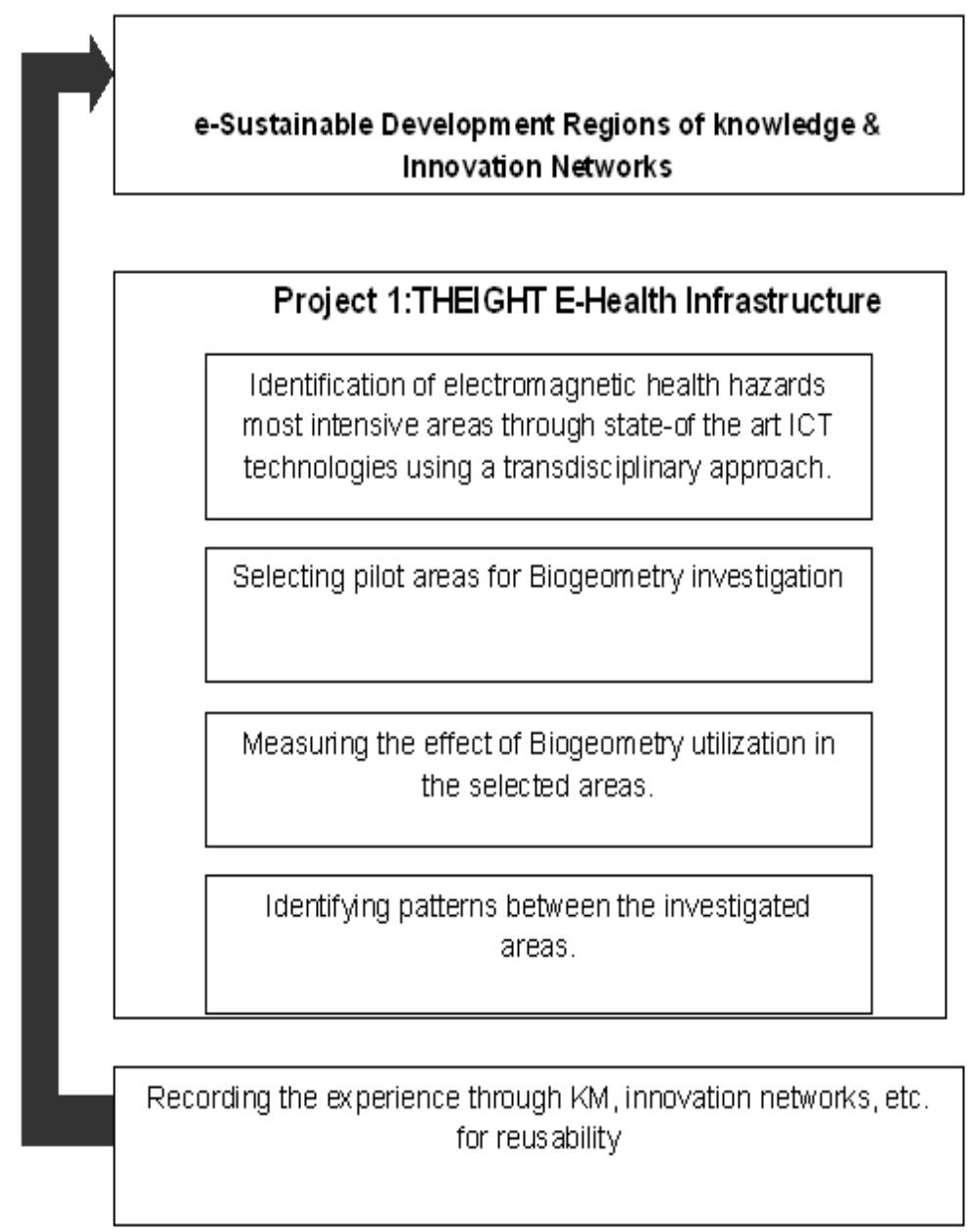

Fig. 1 Suggested TREIGHT Framework

The proposed TREIHT project (shown in fig. 1) will be related to some health hazards in the context of electromagnetic fields to identify the most affected areas and thus develop a supportive infrastructure in these areas to eliminate its effect using the Egyptian expertise of Biogeometry, which has been already transported to Europe, namely Switzerland. BioGeometry ${ }^{\circledR}$ is based on a growing body of scientific research and is an applied science by virtue of its successful applicability in numerous fields. BioGeometry ${ }^{\circledR} \quad$ energy-quality balancing solutions are being applied to architecture, telecom networks, industrial design, boats and airplanes to transmute the effects of environmental energy disturbances from sources such as electro-magnetic radiation, structural design, and cosmic and earthenergy radiation. Pilot research projects under the patronage of the Swiss Mediation Authority for Mobile Communication and Environment (MAMCE), and in collaboration with leading governmental telecom provider Swisscom, implemented BioGeometry ${ }^{\circledR}$ energy-quality balancing to remedy ailments 
of electro-sensitivity in the rural town of Hemberg. Other following projects were successful in eliminating the ailments of electro-sensitivity, among a number of other health conditions that it remedied, as well as positively impacting the overall ecology of the area.

Ethical issues such as the reduction of health inequalities are going to be considered as a high priority. The concept of environmental justice includes the right of all to a healthy environment: poorer environments (with more exposure to pollution, fuel poverty, etc.) and poorer health are found disproportionately amongst the disadvantaged in society. Thus, the selection of the areas to apply biogeometry on will be depending on identifying the most affected areas by analyzing the environmental data through different tools such as the GIS, subject to the availability of supportive data. The project is also aiming to store the knowledge about the management of large scale information systems in the most complex fields such as those related to sustainable development and environmental projects. It is aimed that it will be reusable in the context of other e-health and other none-health application. This will be supportive to the e-government and e-governance development as its extension will allow several areas to be supported.

\section{Conclusions}

This study is part of an attempt for a region of knowledge in e-sustainable development research from a transdisciplinarity perspective. Sustainable development requires an integrated management approach rather than sectorial management and large scale information systems projects involving multidisciplinary specialists and necessitating transdisciplinary collaboration to solve its complex real life problems.

By e-sustainable development we mean large scale information systems projects including the technical and non-technical infrastructure enabling the integration of variable resources, stakeholders, tools, and novel techniques for the purpose of sustainable development.

One of the aspects of sustainable development is the threat of health hazards as the links between health and economic development have become increasingly recognized, especially with respect to the contribution of health to poverty reduction. Furthermore, the growing burden of noncommunicable diseases, as well as the communicable disease burden, has become more evident. Addressing the human dimension of sustainable development is increasingly recognized as fundamental to achieving its goals. Indeed, the first principle of the 1992 Rio Declaration emphasized that "Human beings are at the centre of concerns for sustainable development.

Thus, our suggested framework TREIGHT will be researching sustainable development by broadening the scope of e-Health to include the effects of local environments as additional health factors. Systems thinking will form the basis for the modeling approaches we apply to the problems under consideration. TREIGHT project will model an infrastructure for electromagnetic health hazards prevention using the Biogeometry approach.

The long term goals of our projects is to develop a repository of transdisciplinarity frameworks of knowledge and an accumulation of expertise that will service the needs of e-sustainable development, including e-Health and large scale information systems projects usable not only by Healthcare Institutions, but also aid in creating such structures in developing countries and providing support and training for private company initiatives.

\section{References}

Abdel Aaal, M. (2009). “A Novel Approach to Interior Design Components from the Energy Sciences Perspective," Ph.D. Faculty of Fine Arts, Helwan University. 
Ahmed, N. (2004). "Qualitative Energy Balance in Interior Spaces," Msc. Faculty of Fine Arts, Alexandria University.

Al Borolosy, L. (2007). "Balancing Resonance in Architecture and Urbanization," Msc. Faculty of Engineering, Cairo University.

Al Morsy, I. (2007). "The Role of Environmental Design to Reduce NonPhysical Hazards to Human Health Inside Buildings," Msc. Faculty of Engineering, Mansoura University.

Al Sawy, M. (2004). "Biogeometry and Architecture," Ph.D. Faculty of Engineering, Cairo University.

Antrop, M. \& Rogge, E., (2005). “Evaluation of the Process of Integration in a Transdisciplinary Landscape Study in the Pajottenland (Flanders, Belgium)," Landscape and Urban Planning, 77(2006). 382-392.

Bagli, S., Morra, P. \& G. Spadoni, G. (2004). "The EHHRA Tool: A Decision Support System for Assessing and Managing Human Health Risk from Industrial Activities," Proceedings of 11th international symposium loss prevention, 31 May-3 June 2004, Prague, 1457-1463.

Balsiger, P. W. (2004). "Supradisciplinary Research: History, Objectives and Rationale," Futures, 36 (4). 407-421.

Blanco, G. A. \& Cooper, E. L. (2004). "Immune Systems, Geographic Information Systems (GIS). Environment and Health Impacts," J. Toxicol. Environ. Healt, 7, 465-480.

Bruce, A., Lyall, C., Tait, J. \& Williams, R. (2004). "Interdisciplinary Integration in Europe: The Case of the Fifth Framework Programme“ Futures,). 36, 457-470.

Carlon, C., Critto, A. Marcomini \& Nathanail, P. (2001). "Risk Based Characterisation of Contaminated Industrial Site Using Multivariate and Geostatistical Tools," Environ. Pollut., 111, 417-427.
Caro, D. H. J. (2008). "Deconstructing Symbiotic Dyadic E-Health Networks: Transnational and Transgenic Perspectives," International Journal of Information Management, 4, 94-101.

Cecez-Kecmanovic, D. (2006). "The Discipline of Information Systems-Boundaries Crossed, Boundaries Pushed," Faculty of Management, University of Western Sydney, [Online], [Retrieved January 2, 2010], http://www.sistm.unsw.edu.au/people/dubr avka/CECEZ1.HTM

Dabaeh, M. (2006). "Biogeometry as an Integrated System for the Design of Architectural Spaces," Msc. Faculty of Engineering, Cairo University.

Eikmann, T. \& Herr, C. (2001). "Novellierung der (Muster-) Weiterbildungsordnung - eine neue Herausforderung für die Umweltmedizin?," Umweltmed Forsch Prax, 6 (2001). 1.

Elbir, T, (2004). "A GIS Based Decision Support System for Estimation, Visualization and Analysis of Air Pollution for Large Turkish Cities," Atmos. Environ., 38 (2004). 4509-4517.

Ezz, I., Furlong, S. \& Papazafeiropoulou, A. (2006). "Large Scale E_Government Projects: The Need For Transdisciplinary Collaborating Teams," eGovernment Workshop "06 (eGOV06). Brunel University, London.

Facchinelli, A., Sacchi, E. \& Mallen, L. (2001). "Multivariate Statistical and GIS-Based Approach to Identify Heavy Metal Sources in Soils," Environ. Pollut, 114 (2001). 313-324.

Farouh, H. (2008). "Peace, Energy and Environment for Architectural Morphogenesis," Ph.D. Cairo University.

Farouh, H. (2009). "Harmonizing ElectroSmog in the Built Environment Experimental Project in Hemberg, St. Gallen, Switzerland," Proceedings of the 4th IASME/WSEAS 
international conference on Energy \& environment, 278-283.

Galliers, R. D. (2004). "Trans-disciplinary Research in Information Systems", International Journal of Information Management," 24 (2004). pp. 99-106.

Gilbert , R. J. (2008). “The Hidden Energy Science of Sacred Geometry: Ancient Traditions and Recent Breakthroughs," [Online], [Retrieved January 22, 2010], http://vesica.org/main/sacred-geometry/ sacred-geometry-articles/1027-the-hiddenenergy-science-of-sacred-geometry

Hicks, D. M. \& Katz, J. S. (1996). "Where is Science Going?". Science, Technology \& Human Value, 21 (1996). 379-406.

Horlick-Jones, T. \& Sime, J. (2004). "Living On The Border: Knowledge, Risk and Transdisciplinarity," Futures, 36(4).

Hughes, B. \& Johnston, P. (2005). "Sustainable Futures: Policies For Global Development," Futures, 37, 813-831.

Karim, I. (2002). "Mobile Radiation in Hemberg, Harmonization with Biogeometry," [Online], [Retrieved January 30, 2010], www.biogeometry.com/english/hamberg_st udy.pdf

Karim, I. (2007). Back to A Future for Mankind: Collected Topics on BioGeometry, Ancient Egypt and Solutions to the Modern Environmental Crisis. BioGeometry Energy Systems Limited, Cairo, ISBN: 978-977-623201-3.

Kistemann, D., Dangendorf, F. \& Schweikart, J. (2002). "New Perspectives on the Use of Geographical Information Systems (GIS) in Environmental Health Sciences," International Journal of Hygiene and Environmental Health, 205 (2002). 169-181.

Klein, J. T. (2004). "Prospects for Transdisciplinarity," Futures 36(4).
Lawrence, R. J. \& Després, C. (2004). “Futures of Transdisciplinarity," Futures 36 (4). 397405.

Nam, B. H. S., Eom, K. C., Lee, S. H. \& Smith, A. (2003). "Distribution of Polycyclic Aromatic Hydrocarbons in Agricultural Soils in South Korea," Chemosphere, 50 , 1281-1289.

Newell, S., \& Galliers, R. D. (2000). "More Than a Footnote: The Perils of Multidisciplinary Research Collaboration," Proceedings: AIS Americas Conference, Long Beach, 10-13 August 2000, CA, VOL III 17381742.

Nowotny, H., Scott, P. \& Gibbons, M. (2001). Re-Thinking Science: Knowledge and the Public in an Age of Uncertainty, Polity Press, Cambridge, UK.

Otto, M. \& Hlendahl, K. E. M. (2007). "Electromagnetic Fields (EMF): Do They Play a Role in Children'S Environmental Health (CEH)?," Int. J. Hyg. Environ. Health, 210, 635-644.

Ramadier, J. (2004). "Transdisciplinarity and its Challenges: The Case of Urban Studies," Futures, 36 (4). 423-439.

Röösli, M. (2008). "Radiofrequency Electromagnetic Field Exposure and NonSpecific Symptoms of Ill Health: A Systematic Review," Environmental Research, 107, 277287.

Röösli, M., Moser, M., Baldinini, Y., Meier, M. \&. Braun-Fahrländer, C. (2004). "Symptoms of Ill Health Ascribed to Electromagnetic Field Exposure-A Questionnaire Survey," Int J Hyg Environ Health, 207, 141-150.

Schirnding, Y. (2002). "Health and Sustainable Development: Can We Rise to the Challenge?," The Lancet, 360, 632-637.

Scoggins, A., Kjellstrom, T., Fisher, G., Connor, J. \& Gimson, N. (2004). "Spatial Analysis of Annual Air Pollution Exposure and Mortality," Science of The Total Environment, 321, 71-85. 
Shiha, I. (2009). "The Study of Vital Energy Design of Architectural Spaces in Touristic Villages at the Red Sea," Msc. Matareya Faculty of Engineering.

The Royal Society (1996) Interdisciplinarity-Transport and the Environment, The Royal Society, London.

Thums, C. \& Farago, M. (2001). “Investigating Urban Geochemistry Using Geographical Information Systems," Sci. Prog. 84, 183-204.

Tress, B., Tress, G. \& Fry, G. (2005). "Integrative Studies on Rural Landscapes: Policy Expectations and Research Practice," Landscape and Urban Planning, 70, 177-191.

Wafa, M. (2009). "The Effect of Earth Energy on Architecture," Msc. Faculty of Fine Arts, Alexandria University.

WHO (2006). "Electromagnetic Fields and Public Health," Fact sheet $N^{\circ} 304$, May 2006, [Online], [Retrieved October 2, 2010], http://www.who.int/mediacentre/factsheets /fs304/en/index.html 